\title{
Synthesis, Characterization, and Mesomorphic Behavior of Terminally Carboxyl Oligo(ethylene oxide) Monomethyl Ethers-Substituted Side Chain Liquid Crystalline Copolysiloxane Polymers
}

\author{
Wei-Shan Lee, Guo-Ping Chang-ChIEN, ${ }^{\dagger}$ and Jen-Feng Kuo* \\ Department of Chemical Engineering, Cheng-Shiu College of Technology, Kaohsiung, Taiwan 80741, R.O.C. \\ * Department of Chemical Engineering, National Cheng-Kung University, Tainan, Taiwan 70101, R.O.C.
}

(Received March 20, 1995)

\begin{abstract}
Smectic copolysiloxane polymers can be obtained by co-grafting two smectic monomers onto poly(methyl hydrosiloxane). The ratio of the monomers in the copolymers is characterized by ${ }^{1} \mathrm{H}$ NMR. The mesomorphic properties of copolysiloxane polymers are studied by optical microscopy, DSC, and X-ray diffraction. The effects of the monomer ratio on the liquid crystalline texture, isotropization temperature, enthalpy changes of liquid crystal/isotropic transition, and layer spacing $\left(d_{1}\right)$ of these polymers are discussed.

KEY WORDS Liquid Crystalline/Side Chain/Copolysiloxane Polymers / Schlieren Texture / Smectic Phase / X-Ray Diffraction /
\end{abstract}

Copolymerization appears to be a rather fruitful method of producing new liquid crystalline polymers. ${ }^{1}$ All liquid crystalline copolymers are (a) copolymers obtained by copolymerization of two monomers, one containing a nonmesogenic group ${ }^{2,3}$ (b) copolymers obtained by copolymerization of two mesogenic monomers. ${ }^{4}$ The use of copolymers of cholesterolcontaining alkyl acrylate and methacrylate monomers show that the range of the mesophase is essentially dependent on the length of the alkyl substituent $\mathrm{C}_{n} \mathrm{H}_{2 n+1}$ in the nonmesogenic monomer. With long alkyl substituent $(n=22)$, no mesophase is observed even with a $75 \%$ concentration of the mesogenic component. This may be due to the long alkyl side group screening the mesogenic groups and then inhibiting liquid crystalline phase formation. Ringsdorf and Schneller ${ }^{3}$ grafted a smectic monomer onto the poly[(dimethyl siloxane $)_{x^{-}}$ co-(hydromethyl siloxane) $\left.)_{y}\right]$ copolymer. The minimum concentration of the mesogenic component necessary for liquid crystalline phase formation is $9 \%$. The glass transition temperature increases with hydromethyl siloxane, due to decrease of the distance between the mesogenic groups and thus a change of flexibility of the main chain which is inserted with a bulky molecular into the side chain. The mesophase texture still exhibits the smectic phase. Nonetheless, the introduction of butyl acrylate or isoprene units into a cholesterol-containing smectic homopolymer, which increases the flexibility of the main chain, results in transformation from a smectic to a nematic polymer. ${ }^{10}$ Kostromin and Kozlova ${ }^{4}$ copolymerized smectogenic and nematogenic monomers using identical cyanobiphenyl mesogenic groups: (a) two monomers with different spacer lengths $(n=5$ and $n=11)$ but the same acrylate main chain and (b) two monomers with the same spacer length $(n=5)$ but different main chains (acrylate or methacrylate). For copolymer (a), isotropization temperature $\left(T_{\mathrm{i}}\right)$ and enthalpy change at the $\mathrm{LC}$ /isotropic liquid transition $\left(\Delta H_{\mathrm{i}}\right)$ gradually increase with the concentration of the longer spacer monomer.

\footnotetext{
† To whom all correspondence should be addressed.
}

The transition from the nematic to smectic mesophase takes place at a $30 \%$ concentration of the longer spacer monomer. The thickness of the smectic layer increases linearly with the longer spacer monomer concentration. The results for the copolymer (b) are quite different from those for the copolymer (a). The mesophase remains smectic in the entire range of the composition, and the dependence of $T_{\mathrm{i}}$ and $\Delta H_{\mathrm{i}}$ on the composition has a minimum value. In contrast to monomers containing CN-substituent and alkoxy-substituent mesogenic groups in the terminal, copolymerization leads to a significant increase in the termal stability of the smectic mesophase. ${ }^{5}$ (i.e., from $121^{\circ} \mathrm{C}$ for the homopolymer to $171-177^{\circ} \mathrm{C}$ for the copolymer).

Copolymerization is an effective method of modifying the properties of liquid crystalline polymers by altering their thermal properties. The compositions of copolymers have not been determined in most published studies of monomeric mixtures but are assumed to be equal to the initial monomer feed composition. In the preceding papers, ${ }^{6,7}$ we reported the synthesis of monomers and homopolymers containing phenyl or biphenyl carboxylate benzoate ester based on a mesogenic core with a carboxylate $( \pm) 2$-methyl ethylene glycol monomethyl ether group or a carboxyl oligo(ethylene oxide) monomethyl ether as the terminal group. Here we report the results of the synthesis of copolymers containing phenyl or biphenyl carboxylate benzoate ester based on the mesogenic core. In the present research, we use ${ }^{1} \mathrm{H}$ NMR to analyze the composition of the copolymer and study the effects of monomer composition on the liquid crystalline texture, isotropization temperature, enthalpy change of mesophase/isotropic liquid transition, and layer spacing in the liquid crystalline phase.

\section{EXPERIMENTAL}

\section{Materials}

The synthesis and characterization of the monomers used in this study are described elsewhere. ${ }^{6.7}$ 
Synthesis of Copolysiloxane Polymers

The synthesis method for all the copolysiloxane polymers was the same procedure, ${ }^{6}$ as follows: $0.02 \mathrm{~mol}$ of poly(methyl hydrosiloxane) $\left(\overline{D P}=35, \bar{M}_{w}=2268\right)$ and $10 \mathrm{~mol} \%$ excess of monomer mixtue were dissolved in $5 \mathrm{ml}$ of sodium-dried toleuene. $10 \mu \mathrm{l}$ of $7.5 \times 10^{-3} \mathrm{M}$ chloroplatinic acid isopropanol solution were added to the above solution. The reaction temperature was kept at $80^{\circ} \mathrm{C}$, and the disappearance of the $\mathrm{Si}-\mathrm{H}$ IR band at $2165 \mathrm{~cm}^{-1}$ (about $24 \mathrm{~h}$ ) was monitored. Polymers were purified by methanol precipitation and $\mathrm{CH}_{2} \mathrm{Cl}_{2}$ redissolution three times, then dried under vacuum at room temperature.

\section{Techniques}

${ }^{1} \mathrm{H}$ NMR spectra were recorded on a Bruker AC200 $(200.13 \mathrm{MHz})$ from $\mathrm{CDCl}_{3}$ solution with tetramethylsilane (TMS) as the internal standard. The phase transition temperatures of the copolysiloxane polymers were studied with a Dupont 910 differential scanning calorimeter (DSC). A 9900 computer system was used to read temperature and heat effect when thermal transition occurred. The textures of the copolysiloxane polymers were observed under an Olympus BH-2 polarized optical microscope equipped with a LINKAM THMS 600 hot stage and a TMS 91 central processor. X-Ray studies were performed with a Siemens Diffraktometer D5000 apparatus $(40 \mathrm{kV}, 30 \mathrm{~mA})$. Nickel-filtered $\mathrm{Cu}-K_{\alpha}$ radiation was used.

The intensity of scattered X-rays from the sample was measured by a scintillation counter. The diffractometer scanned a range of $2^{\circ}<2 \theta<30^{\circ}$ with a scanning speed of $0.05^{\circ} / 0.1 \mathrm{~s}$. X-ray diffractograms and photomicrographs were obtained at $10^{\circ} \mathrm{C}$ below the isotropization temperature.

Composition Analysis of Copolysiloxane Polymers I

Figure 1 illustrates a typical ${ }^{1} \mathrm{H}$ NMR spectrum of copolysiloxane polymer I for the feed composition MNA4C(30\%)/ME1S3KA(70\%). Composition analysis of copolymers was derived from the areas of the appropriate peaks. The calculation method is illustrated below. Peaks at $3.0-6.0 \mathrm{ppm}$ correspond to the following groups:

$$
\begin{aligned}
\delta(5.31 \mathrm{ppm}): & -\mathrm{COOC}^{*}\left(\mathrm{CH}_{3}\right) \mathrm{CH}_{2} \mathrm{OCH}_{3}(\mathrm{ME} 1 \mathrm{~S} 3 \mathrm{KA}) \\
\delta(4.31 \mathrm{ppm}): & -\mathrm{CH}_{2} \mathrm{O}-\mathrm{Ph}-(\mathrm{ME} 1 \mathrm{~S} 3 \mathrm{KA}) \\
& -\mathrm{CH}_{2} \mathrm{O}-\mathrm{Ph}-(\mathrm{MNA} 4 \mathrm{C}) \\
\delta(3.95 \mathrm{ppm}): & -\mathrm{COOC}_{2} \mathrm{CH}_{2} \mathrm{OC}_{2} \mathrm{H}_{4} \mathrm{OCH}_{3} \text { (MNA4C) } \\
\delta(3.53 \mathrm{ppm}): & -\mathrm{COOCH}_{2} \mathrm{CH}_{2} \mathrm{OC}_{2} \mathrm{H}_{4} \mathrm{OCH}_{3} \text { (MNA4C) } \\
& -\mathrm{COOCH}^{*}\left(\mathrm{CH}_{3}\right) \mathrm{CH}_{2} \mathrm{OCH}_{3} \text { (ME1S3KA) } \\
\delta(3.41 \mathrm{ppm}): & -\mathrm{COOCH}_{2} \mathrm{CH}_{2} \mathrm{OC}_{2} \mathrm{H}_{4} \mathrm{OCH}_{3} \text { (MNA4C) } \\
& -\mathrm{COOCH}^{*}\left(\mathrm{CH}_{3}\right) \mathrm{CH}_{2} \mathrm{OCH}_{3} \text { (ME1S3KA) }
\end{aligned}
$$

The molar composition of the copolysiloxane polymer I is given by

$$
\mathrm{ME} 1 \mathrm{~S} 3 \mathrm{KA}=\frac{\delta(5.31 \mathrm{ppm})}{\mathrm{SUMA}} \times 100 \%
$$

where

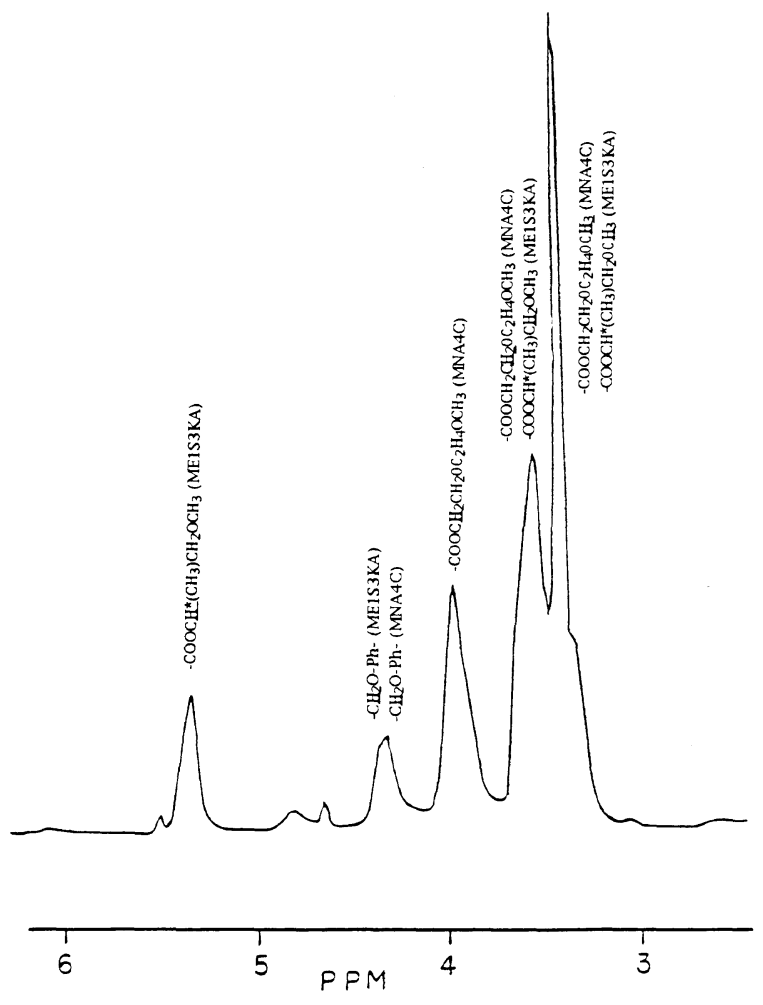

Figure 1. $200 \mathrm{MHz}{ }^{1} \mathrm{H}$ NMR spectrum for the copolymer I of the molar composition MNA4C (21.7\%)/ME1S3KA (78.3\%).

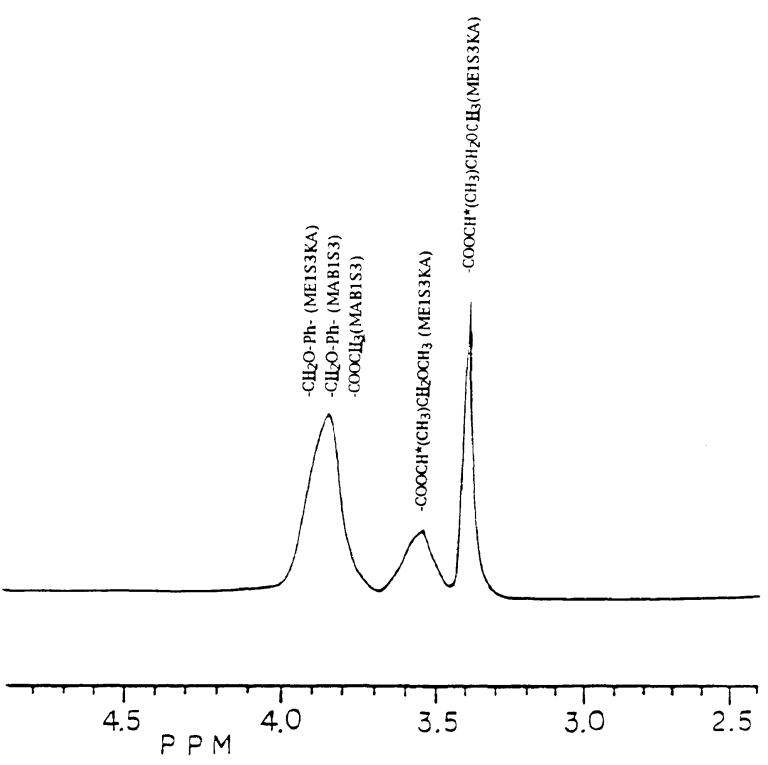

Figure 2. $200 \mathrm{MHz}{ }^{1} \mathrm{H}$ NMR spectrum for the copolymer II of the composition MEIS3KA (53.5\%)/MAB1S3 (46.5\%).

$$
\begin{aligned}
\text { SUMA }= & \delta(5.31 \mathrm{ppm})+\frac{1}{10} \times[\delta(4.31 \mathrm{ppm}) \\
& +\delta(3.95 \mathrm{ppm})+\delta(3.53 \mathrm{ppm})+\delta(3.41 \mathrm{ppm}) \\
& -7 \times \delta(5.31 \mathrm{ppm})]
\end{aligned}
$$

The compositions of the copolysiloxane polymers are listed in Table II.

\section{Composition Analysis of Copolysiloxane Polymers II}

Figure 2 illustrates a typical ${ }^{1} \mathrm{H}$ NMR spectrum of copolysiloxane polymer II for the feed composition ME1S3KA(70\%)/MAB1S3(30\%). The composition 
analysis of copolymers was derived from the areas of the appropriate peaks. The peaks at $3.2-4.5 \mathrm{ppm}$ correspond to the following groups.

\section{$\delta(3.41 \mathrm{ppm}):-\mathrm{COOCH}^{*}\left(\mathrm{CH}_{3}\right) \mathrm{CH}_{2} \mathrm{OCH}_{3}(\mathrm{ME} 1 \mathrm{~S} 3 \mathrm{KA})$ $\delta(3.54 \mathrm{ppm}):-\mathrm{COOCH}^{*}\left(\mathrm{CH}_{3}\right) \mathrm{CH}_{2} \mathrm{OCH}_{3}(\mathrm{ME} 1 \mathrm{~S} 3 \mathrm{KA})$ $\delta(3.88 \mathrm{ppm}):-\mathrm{CH}_{2} \mathrm{O}-\mathrm{Ph}-(\mathrm{ME} 1 \mathrm{~S} 3 \mathrm{KA})$ $-\mathrm{C}_{2} \mathrm{O}-\mathrm{Ph}(\mathrm{MAB} 1 \mathrm{~S} 3)$ $-\mathrm{COOCH}_{3}(\mathrm{MAB} 1 \mathrm{~S} 3)$}

The molar composition of the copolysiloxane polymer II is given by:

$$
\text { ME1S3KA }=\frac{\delta(3.41 \mathrm{ppm}) \times \frac{1}{3}}{\text { SUMA }} \times 100 \%
$$

where

$$
\begin{aligned}
\text { SUMA }= & \frac{1}{3} \times \delta(3.41 \mathrm{ppm})+[\delta(3.54 \mathrm{ppm}) \\
& \left.+\delta(3.88 \mathrm{ppm})-\frac{\delta(3.41 \mathrm{ppm})}{3} \times 4\right] \times \frac{1}{5}
\end{aligned}
$$

The compositions of the copolysiloxane polymers II are listed in Table III.

Composition Analysis of Copolysiloxane Polymers III

Figure 3 illustrates a typical ${ }^{1} \mathrm{H}$ NMR spectrum of copolysiloxane polymer III for the feed composition ME2S3(20\%)/MAB1S3(80\%). Composition analysis of copolymers was carried out as described above. The peaks at $3.2-4.0 \mathrm{ppm}$ correspond to the following groups:

$\delta(3.39 \mathrm{ppm}):-\mathrm{COO}\left(\mathrm{C}_{2} \mathrm{H}_{4} \mathrm{O}\right)_{2} \mathrm{OC}_{3}(\mathrm{ME} 2 \mathrm{~S} 3)$

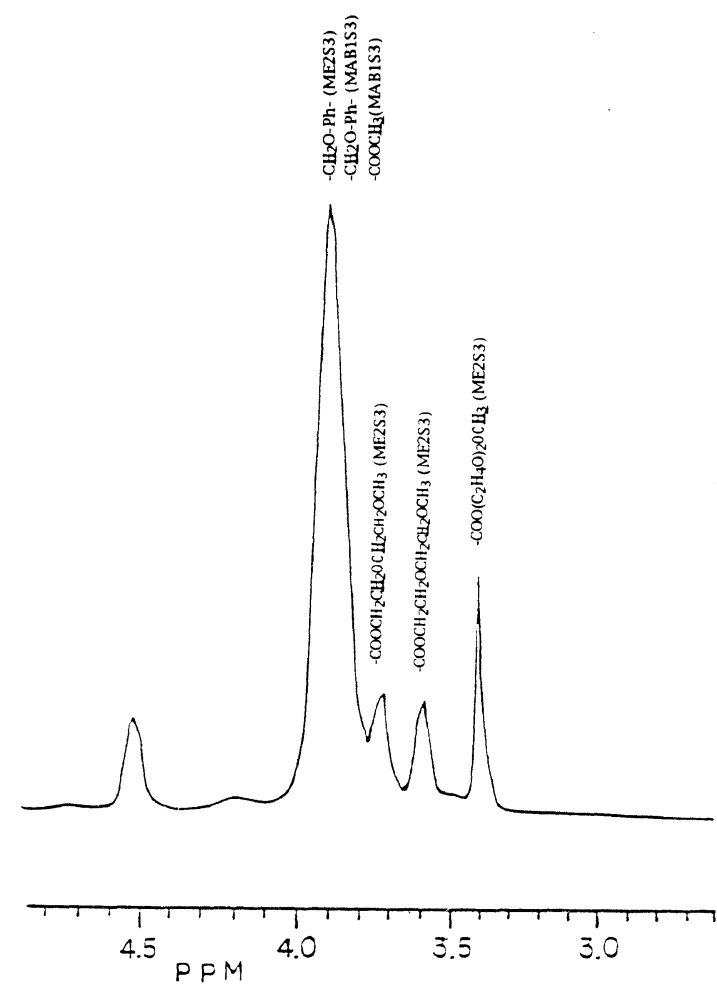

Figure 3. $200 \mathrm{MHz}{ }^{1} \mathrm{H}$ NMR spectrum for copolymer III of the composition ME2S3 (24.5\%)/MAB1S3 (75.5\%).

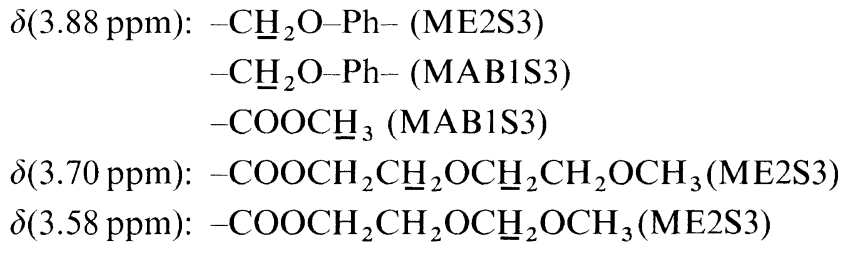

The molar composition of the copolysiloxane polymer III is given by:

$$
\mathrm{ME} 2 \mathrm{~S} 3=\frac{\delta(3.39 \mathrm{ppm}) \times \frac{1}{3}}{\mathrm{SUMA}} \times 100 \%
$$

where

$$
\begin{aligned}
\text { SUMA }= & \frac{1}{3} \times \delta(3.39 \mathrm{ppm})+\frac{1}{5} \times[\delta(3.88 \mathrm{ppm}) \\
& +\delta(3.70 \mathrm{ppm})+\delta(3.58 \mathrm{ppm})-\frac{8}{3} \\
& \times \delta(3.39 \mathrm{ppm})]
\end{aligned}
$$

The compositions of the copolysiloxane polymers III are listed in Table IV.

\section{RESULTS AND DISCUSSION}

Table I shows the molecular structures, phase transition temperatures, and mesophase type of the monomers and corresponding homopolymers characterized by ${ }^{1} \mathrm{H}$ NMR, DSC, polarized optical microscopy, and X-ray diffraction method. ${ }^{6,7}$ The monomer ME1S3KA has a carboxyl $( \pm) 2$-methyl ethylene glycol monomethyl ether terminal group. The monomer ME1S3KA and its polymeric homologue PE1S3KA exhibited a smectic phase. The monomer ME2S3 showed a smectic phase and nematic phase, whereas its polymeric homologue

Table I. Nomenclature, molecular structure, phase transition temperature, and mesophase type of the monomers and corresponding homopolymers

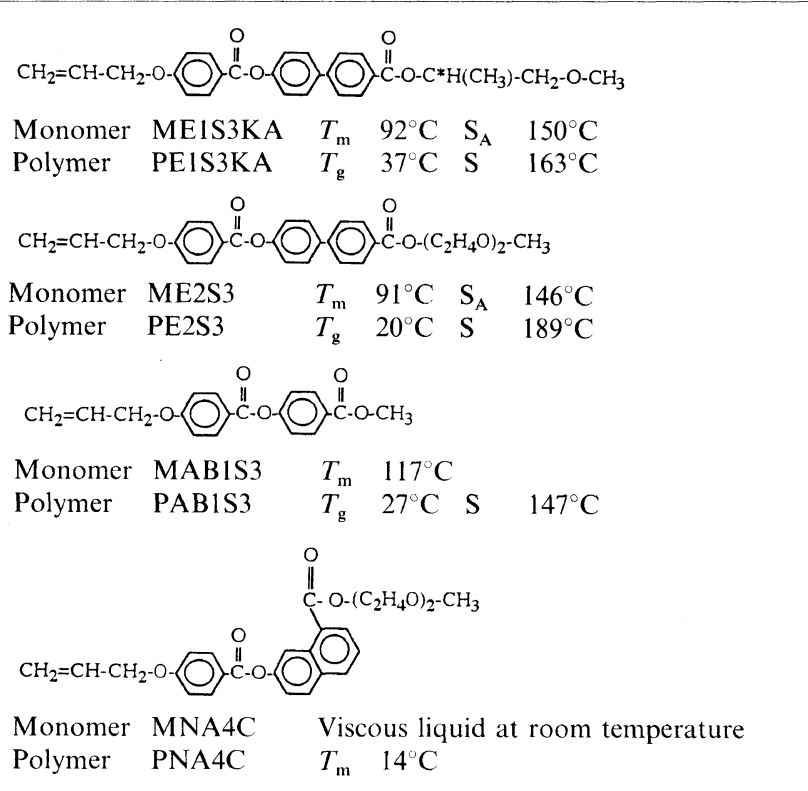


shows only a smectic phase. In comparison to the monomers ME1S3KA and ME2S3, the monomer MAB1S3 has a shorter mesogenic group. It showed no liquid crystalline properties, whereas its polymeric homologue, a smectic phase. The monomer MNA4C had a wider mesogenic group and longer substituent on the mesogenic group than the monomers ME1S3KA and ME2S3. The monomer MNA4C and its polymeric homologue did not show any liquid crystalline properties. By using standard bond lengths and valence angles, the total length of side chains estimated for the homopolymers PE1S3KA, PE2S3, and PAB1S3 were respectively $25.3 \AA, 28.7 \AA$, and $18.8 \AA$. A tilted packing is proposed for these homopolymers above. ${ }^{11}$

Scheme I outlines the procedure and monomer pairs for the preparation of the copolysiloxane polymers. The copolysiloxane polymers were (a) copolymers I, obtained by copolymerization of two monomers, one of which containing a nonmesogenic component (MNA4C)

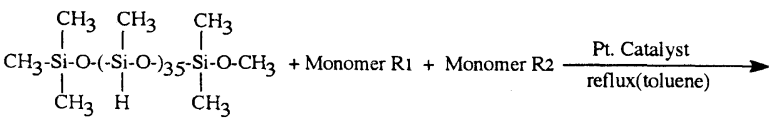

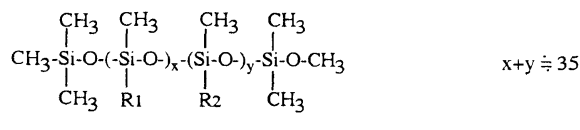

$$
\begin{aligned}
& \begin{array}{llll} 
& & \mathrm{R} 1 & \mathrm{R} 2 \\
\text { Copolymer } & \text { I } & \text { MNA4C } & \text { ME1S3KA } \\
\text { Copolymer } & \text { II } & \text { ME1S3KA } & \text { MAB1S3 } \\
\text { Copolymer } & \text { III } & \text { ME2S3 } & \text { MAB1S3 }
\end{array}
\end{aligned}
$$

Scheme 1. Synthesis procedure and monomer pairs used for the preparation of liquid crystalline copolysiloxane polymers. and the other one containing a smectogenic component (ME1S3KA), and (b) copolymers II and III, obtained by the copolymerization of two smectogenic monomers. Full experimental DSC thermograms of the homopolymers and copolymers can be seen elsewhere. ${ }^{12}$ The composition, glass transition temperature, isotropization temperature, mesophase type, and layer spacing of copolysiloxane polymers were characterized by ${ }^{1} \mathrm{H}$ NMR, DSC, polarized optical microscopy, and X-ray diffraction, respectively. The results are summarized in Tables II, III, and IV. It can be seen from these tables that the compositions of the copolysiloxane polymers do not correspond to the initial feed composition.

\section{Relation between Liquid Crystalline Properties and Compositions of the Copolymers I}

Figure 4 shows X-ray diffraction diagrams of the copolymers I with the compositions: MNA4C(11.7\%)/ ME1S3KA(88.3\%), MNA4C $(21.7 \%) / \mathrm{ME} 1 \mathrm{~S} 3 \mathrm{KA}$ $(78.3 \%)$, and MNA4C(45.1\%)/ME1S3KA(54.9\%). The corresponding layer spacing values $d_{1}$ can be obtained by using the Bragg equation $2 d_{1} \sin \theta=\lambda_{1}\left(\lambda_{1}=1.542 \AA\right)$. Figure 5 illustrates polarized optical micrographs for the homopolymer MNA4C(0\%)/ME1S3KA(100\%) and the copolymer MNA4C $(11.7 \%) / \mathrm{ME} 1 \mathrm{~S} 3 \mathrm{KA}(88.3 \%)$. Figure 6 demonstrates the relation of glass transition temperature $\left(T_{\mathrm{g}}\right)$ and isotropization temperature with the composition for the copolymer I. Table I summarizes mesophase properties and layer spacings of copolymers I. Figure 5 shows that polymers I exhibit a birefringent texture under polarized optical microscope and the X-ray diagrams show a small angle reflection which is the characteristic of smectic phases. However, an increase in nonmesogenic component MNA4C results in the

Table II. Copolymer composition $(\mathrm{mol} \%)$, glass transition temperature $\left({ }^{\circ} \mathrm{C}\right)$, isotropization temperature $\left({ }^{\circ} \mathrm{C}\right)$, and enthalpy change $\left(\mathrm{Jg}^{-1}\right)$ of the mesophase/isotropic liquid transition, layer spacing $(\AA)$ and phase type for the copolymers I

\begin{tabular}{|c|c|c|c|c|c|c|c|c|c|}
\hline \multicolumn{2}{|c|}{ Feed composition } & \multicolumn{2}{|c|}{ Copolymer composition } & \multirow{2}{*}{$T_{\mathrm{g}}$} & \multirow{2}{*}{$T_{\mathrm{i}}$} & \multirow{2}{*}{$\begin{array}{l}\text { Enthalpy } \\
\text { change }\end{array}$} & \multirow{2}{*}{$\begin{array}{l}\text { Entropy } \\
\text { change }\end{array}$} & \multirow{2}{*}{$d_{1}$} & \multirow{2}{*}{ Phase type } \\
\hline Rl & $\mathrm{R} 2$ & R1 & $\mathrm{R} 2$ & & & & & & \\
\hline 10 & 90 & 11.7 & 88.3 & 19.5 & 152 & 1.97 & 4.63 & 24.7 & Smectic \\
\hline 30 & 70 & 21.7 & 78.3 & 26.5 & 104 & 0.56 & 1.48 & 23.3 & Smectic \\
\hline 50 & 50 & 45.1 & 54.9 & 19.1 & & & & & No mesophase \\
\hline 100 & 0 & 100.0 & 0.0 & 14.0 & & & & & No mesophase \\
\hline
\end{tabular}

Table III. Copolymer composition $(\mathrm{mol} \%)$, glass transition temperature $\left({ }^{\circ} \mathrm{C}\right)$, isotropization temperature $\left({ }^{\circ} \mathrm{C}\right)$, enthalpy change $\left(\mathrm{J} \mathrm{g}^{-1}\right)$ and entropy change $\left(\mathrm{J} \mathrm{kg}^{-1} \mathrm{~K}^{-1}\right)$ of the mesophase/isotropic liquid transition, layer spacing $(\AA)$ and mesophase type for the copolymers II

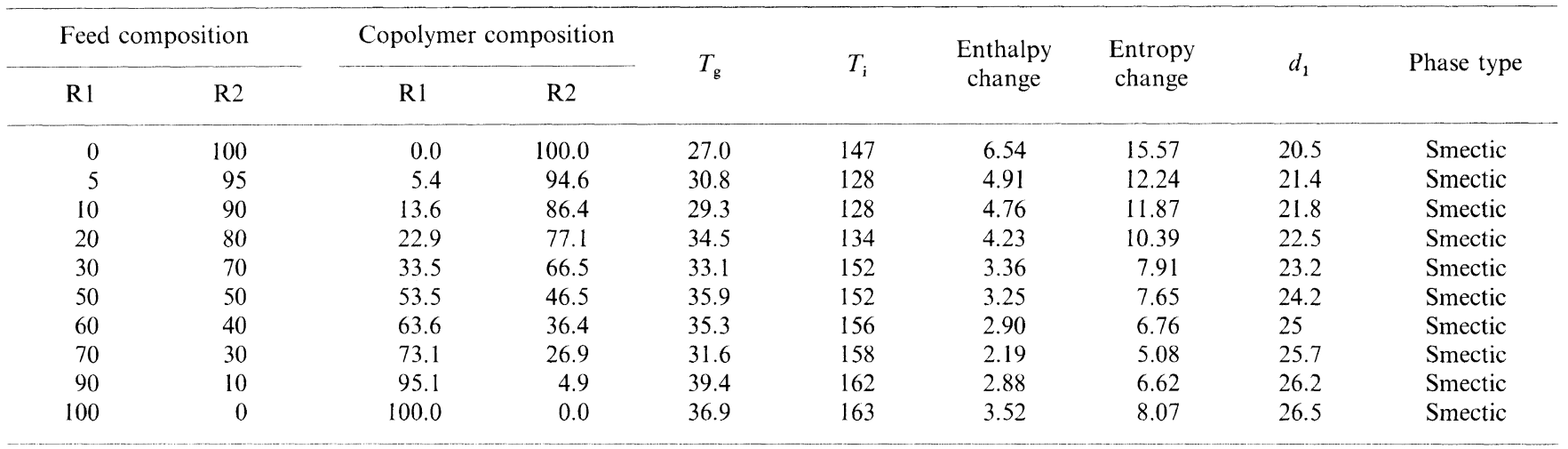


Table IV. Copolymer composition $(\mathrm{mol} \%)$, glass transition temperature $\left({ }^{\circ} \mathrm{C}\right)$, isotropization temperature $\left({ }^{\circ} \mathrm{C}\right)$, enthalpy change $\left(\mathrm{J} \mathrm{g}^{-1}\right)$, and entropy change $\left(\mathrm{J} \mathrm{kg}^{-1} \mathrm{~K}^{-1}\right)$ of the mesophase/isotropic liquid transition, layer spacing $(\AA)$ and mesophase type for the copolymers III

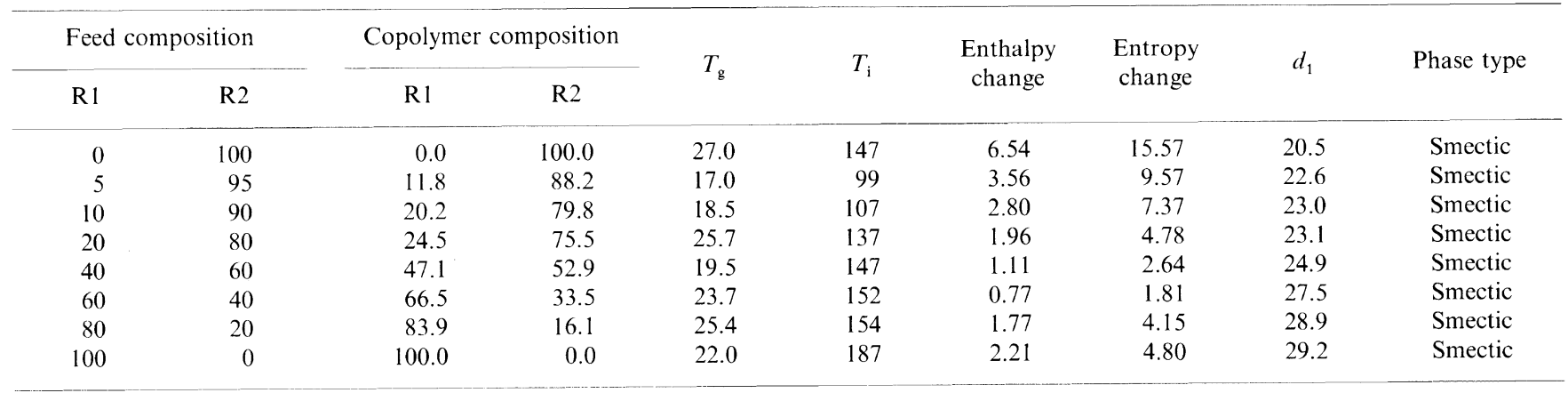

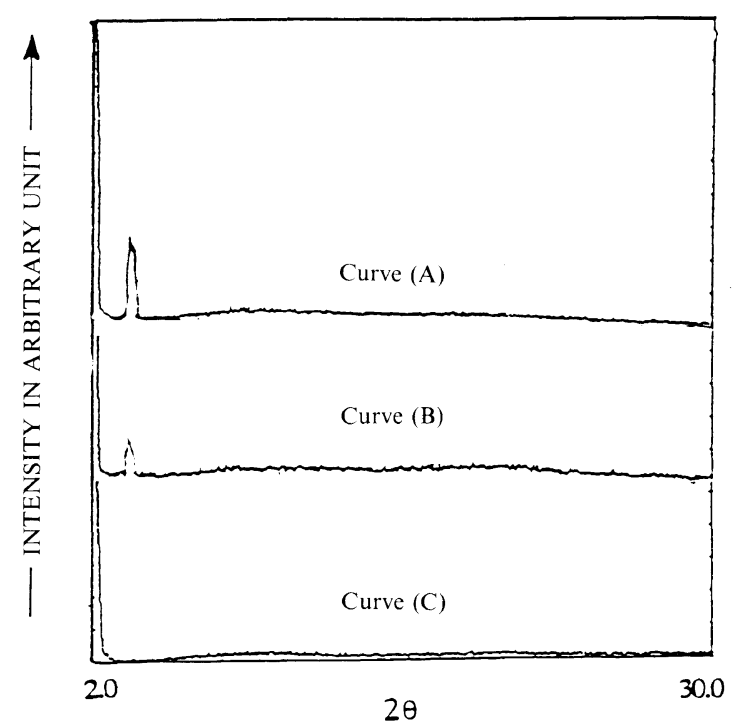

Figure 4. X-ray diffraction diagrams for copolymers I. Compositions: (A) $11.7 \% / 88.3 \%$; (B) $21.7 \% / 78.3 \%$; (C) $45.1 \% / 54.9 \%$.

disappearance of the small angle reflection. Gemmell et $a l .{ }^{8}$ prepared copolymers using a 2-methyl-substituted ester monomer and a smectic monomer. They obtained nematic copolymers when the 2-methyl-substituted component concentration reached $68 \%$. In this study, we could not obtain liquid crystalline nematic phases by using a monomer with a lateral carboxyl diethylene glycol monomethyl ether group. As illustrated in Table I, as the concentration of MNA4C increases, the temperature range of the mesophase $\left(T_{\mathrm{i}}-T_{\mathrm{g}}\right)$, the enthalpy change $\left(\Delta H_{\mathrm{i}}\right)$ and entropy change $\left(\Delta S_{\mathrm{i}}\right)$ of the transition, and the layer spacing decrease, possibly due to the bulky and asymmetric molecules incorporated into the side chains which results in reduced flexibility of the polymer backbone.

\section{Relation between Liquid Crystalline Properties and Compositions of Copolymers II and III}

Figure 7 shows polarized optical micrographs for homopolymer $0 \% / 100 \%(\mathrm{ME} 1 \mathrm{~S} 3 \mathrm{KA} / \mathrm{MAB} 1 \mathrm{~S} 3)$ and copolymer II of composition $13.6 \% / 86.4 \%$ (ME1S3KA/ MAB1S3). Figure 8 illustrates polarized optical micrographs for homopolymer $100 \% / 0 \%(\mathrm{ME} 2 \mathrm{~S} 3 / \mathrm{MAB} 1 \mathrm{~S} 3)$ and copolymer III of composition $47.1 \% / 52.9 \%$ (ME2S3/ MAB1S3). Figures 9 and 10 show small angle X-ray diagrams of copolymers II and III of different com-

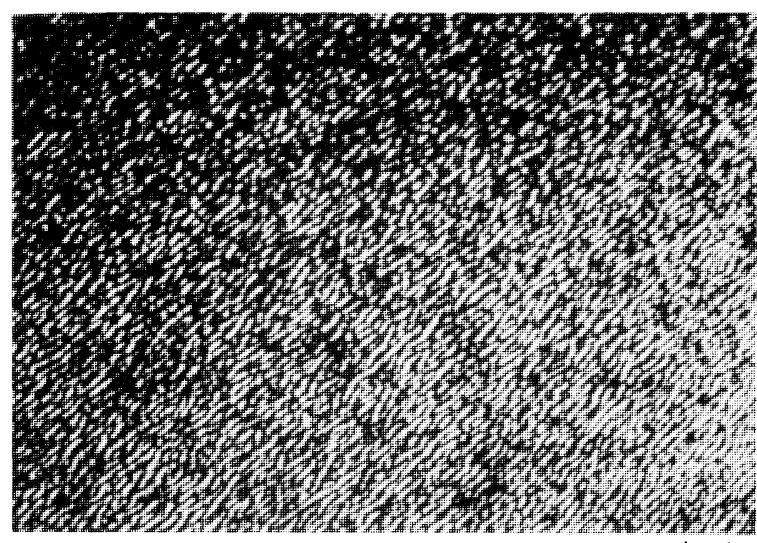

(A) $0 \% / 100 \%(M N A 4 C / M E 1 S 3 K A)$

$\underset{25 \mu M}{\longmapsto}$

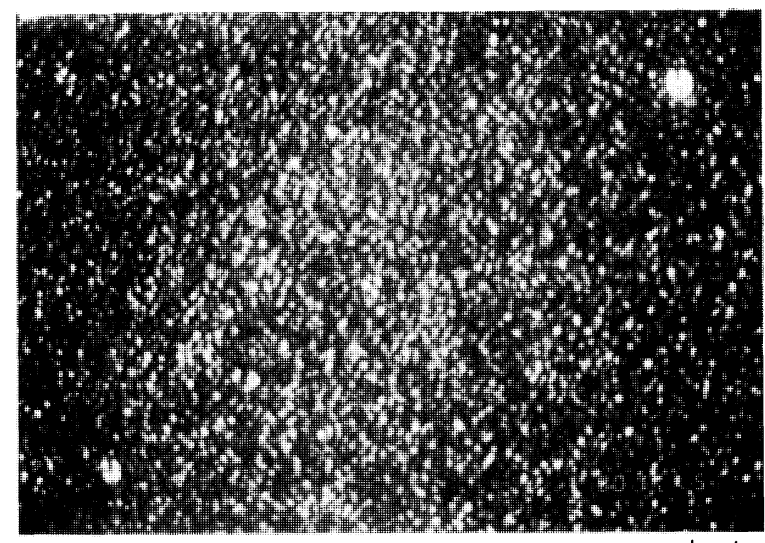

(B) $11.7 \% / 88.3 \%(M N A 4 C / M E 1 S 3 K A)$

Figure 5. Polarized optical micrographs for the copolymers I. Composition: (A) $0 \% / 100 \%$ (MNA4C/ME1S3KA) and (B) $11.7 \%$ $88.3 \%$ (MNA4C/ME1S3KA).

positions, respectively. Tables III and IV summarize mesophase properties and layer spacings for copolymers II and III, respectively. Figures 12 and 13 demonstrate the relation between isotropization temperature enthalpy change of the mesophase/isotropic liquid transition, and layer spacing and the copolymer composition. As seen from Figures 11 and $12, T_{\mathrm{i}}$ and $\Delta H_{\mathrm{i}}$ quickly decrease and reach a minimum value at $20 \%$ and $50 \%$ of the $R_{1}$ monomer, respectively. This could be the consequence of more defective packing of side groups due to the incorporation of units of different chemical nature in the backbone. The situation is different for copolymers with $\mathrm{CN}$ - and alkoxy-substituted mesogenic groups. ${ }^{5}$ It was observed that copolymerization leads to a significant 


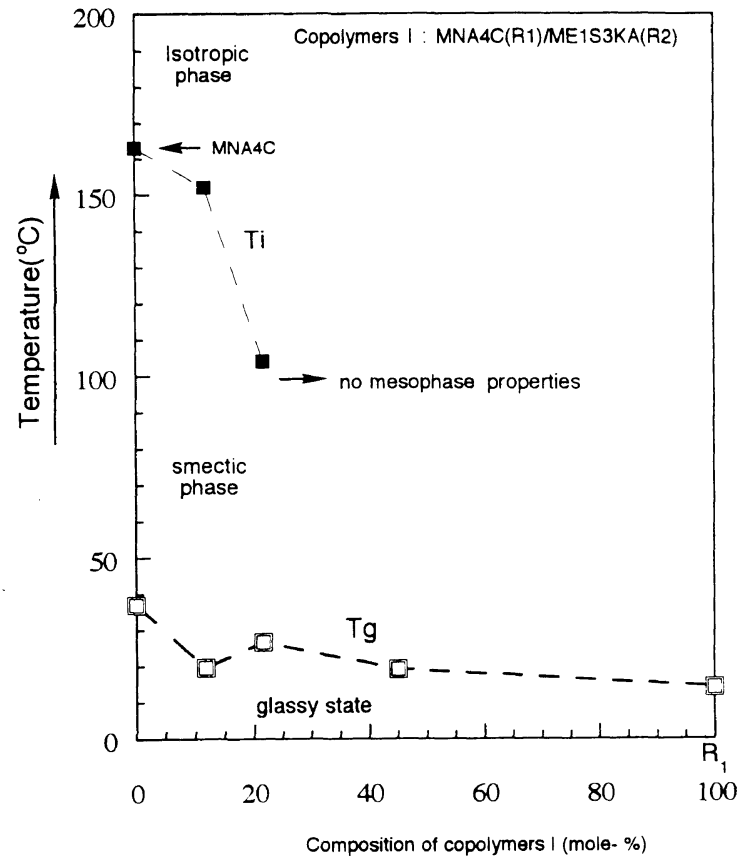

Figure 6. Relationships between the glass transition temperature $\left(T_{\mathrm{g}}\right)$, the isotropization temperature $\left(T_{\mathrm{i}}\right)$, and compositions of the copolymers
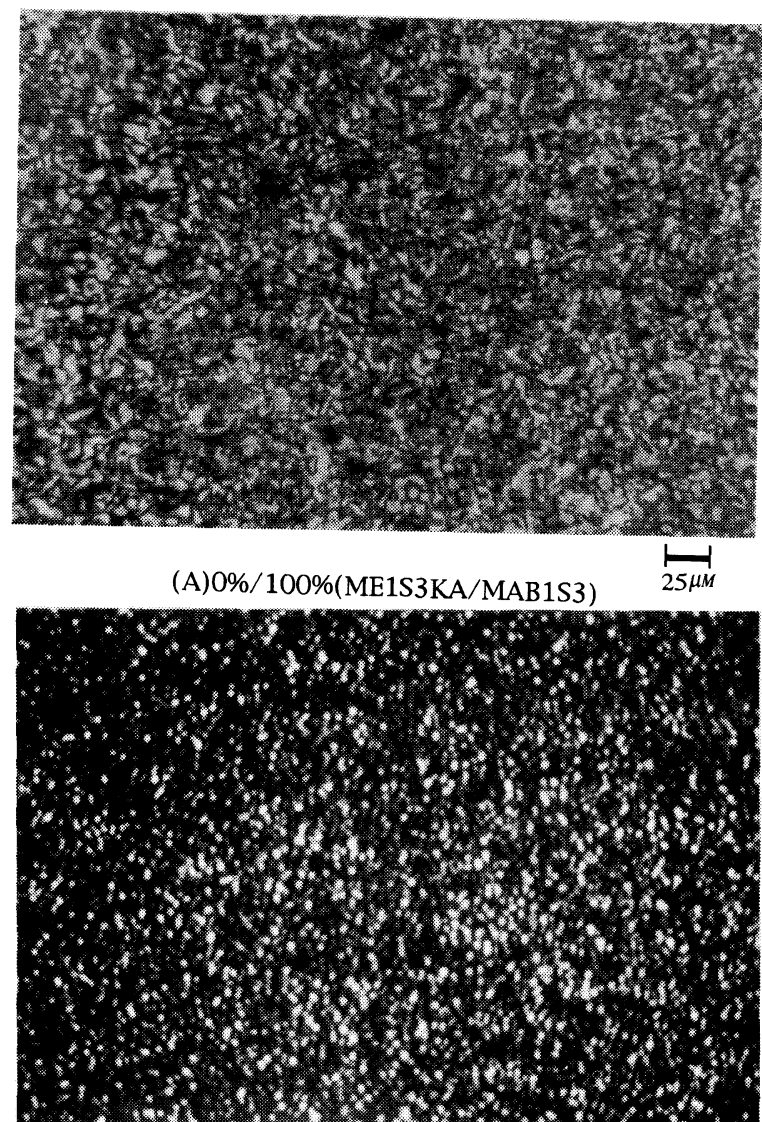

(B) $13.6 \% / 86.4 \%$ (ME1S3KA/MAB1S3)

Figure 7. Polarized optical micrographs for the copolymers II Composition: (A) $0 \% / 100 \%$ (ME1S3KA/MAB1S3) and (B) $13.6 \%$ 86.4 (ME1S3KA/MAB1S3).

increase of the smectic mesophase thermostability. It can be seen from polarized optical micrographs (Figure 7) that copolymers II exhibit a smectic phase over the Polym. J., Vol. 28, No. 3, 1996

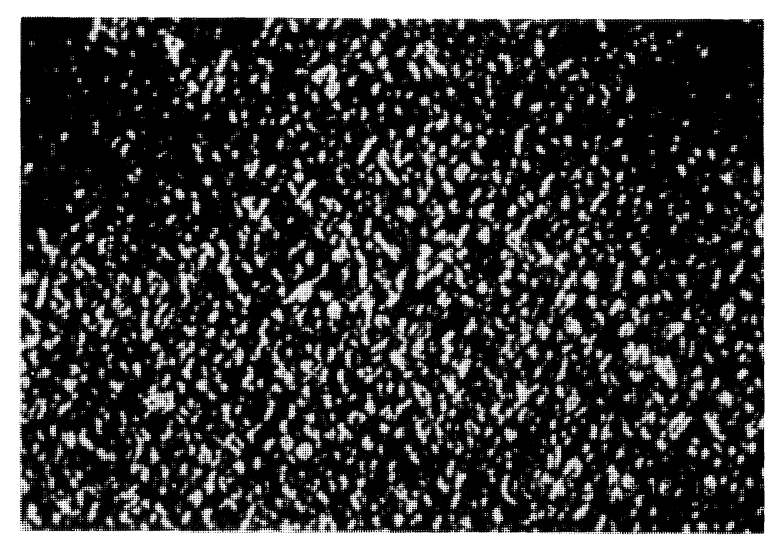

(A) ME2S3/MAB1S3(100\%/0\%)

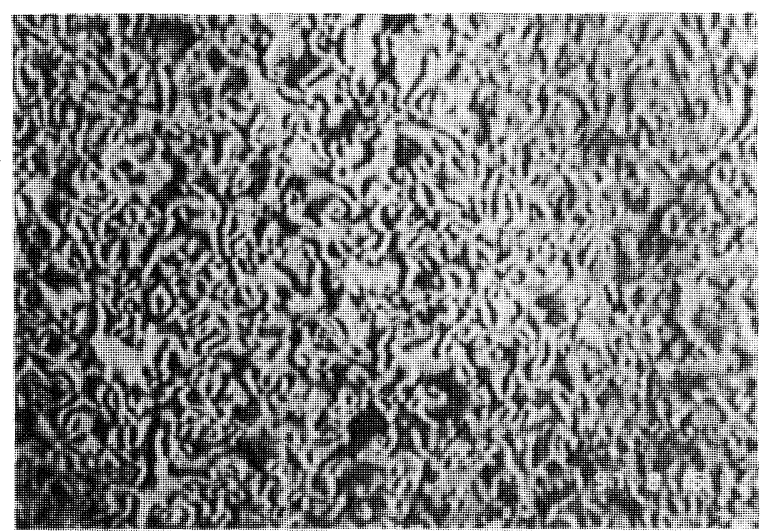

(B) ME2S3/MAB1S3 (47.1\%/52.9\%) $25 \mu \mathrm{M}$

Figure 8. Polarized optical micrographs for the copolymers III Composition: (A) $100 \% / 0 \%$ (ME2S3/MAB1S3) and (B) $47.1 \% / 52.9 \%$ (ME2S3/MAB1S3).

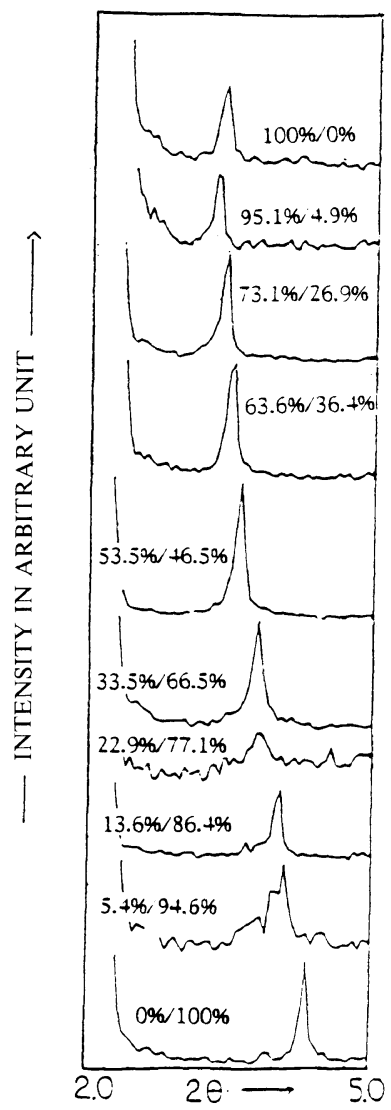

Figure 9. The X-ray diffraction diagrams for the copolymers II of various molar compositions. 
W.-S. LeE, G.-P. C-Chien, and J.-F. Kuo

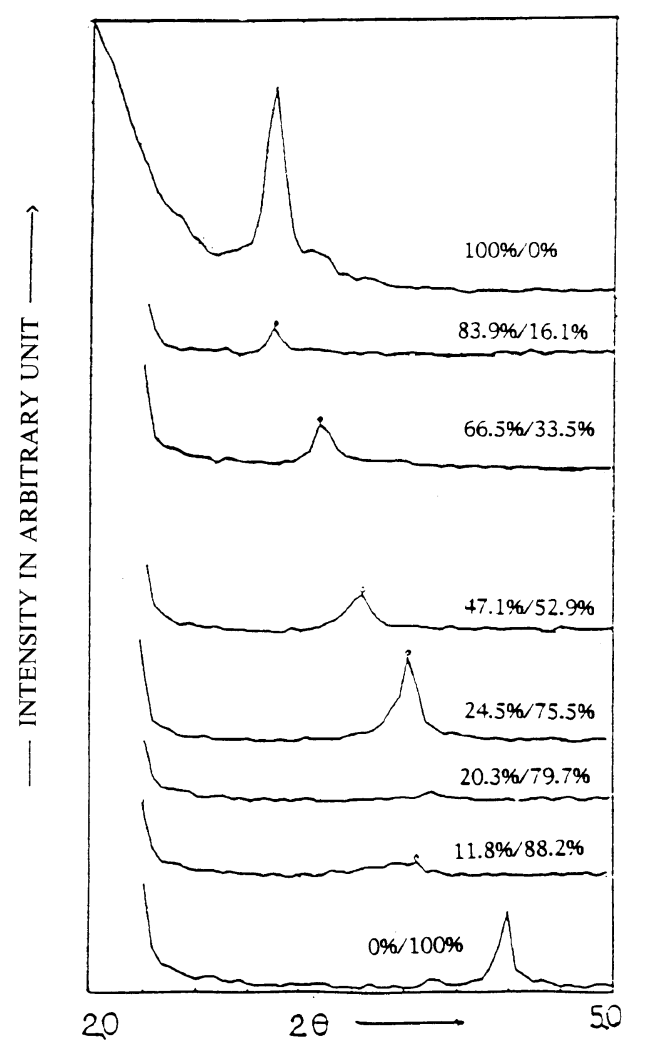

Figure 10. The X-ray diffraction diagrams for copolymers III of various molar compositions.

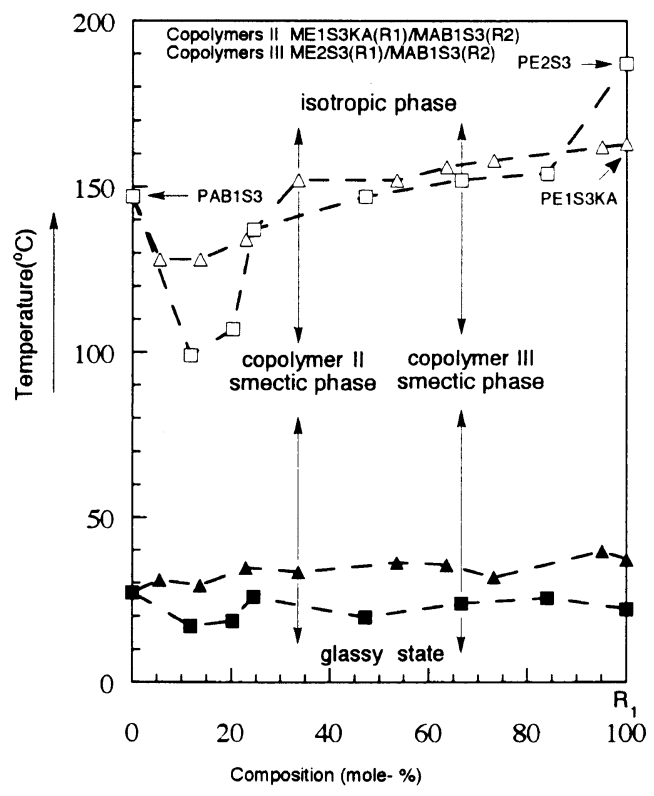

Figure 11. Relationships between the glass transition temperature $\left(T_{\mathrm{g}}\right)$, isotropization temperature $\left(T_{\mathrm{i}}\right)$, and molar compositions of copolymers II and III.

whole range of composition. The textures of copolymers III (Figure 8) resemble those of the nematic phases for the compositions ME2S3(66.5\%)/MAB1S3(33.5\%) and ME2S3(47.1\%)/MAB1S3(52.9\%). $\Delta H_{\mathrm{i}}$ of copolymers III of the above compositions dropped to less than $1.0 \mathrm{~J} \mathrm{~g}^{-1}$. These observations are indication of a nematic phase for these copolymers III. However, it can be seen that the correponding X-ray diffraction curves still show sharp reflection in the small angle region which is characteris-

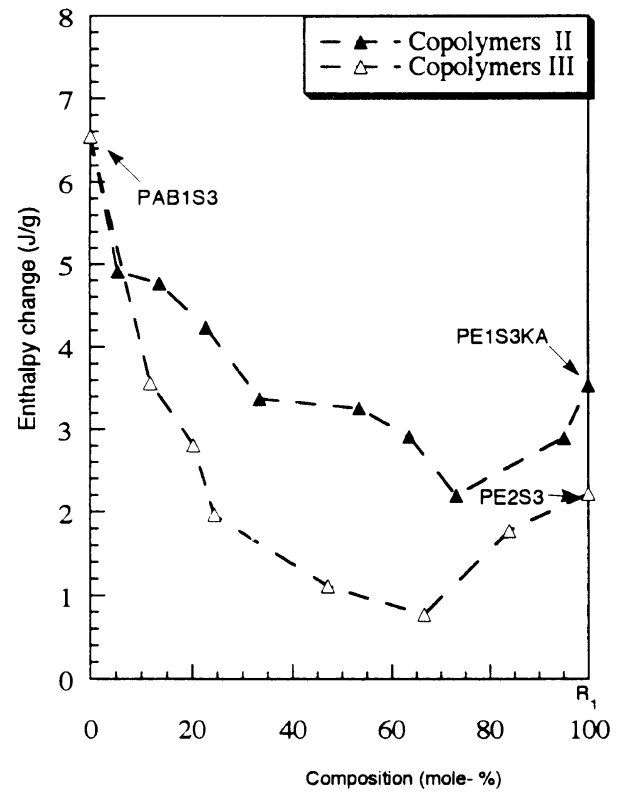

Figure 12. Relationships between the enthalpy change of mesophase/isotropic liquid transition and molar composition of copolymers II and III.

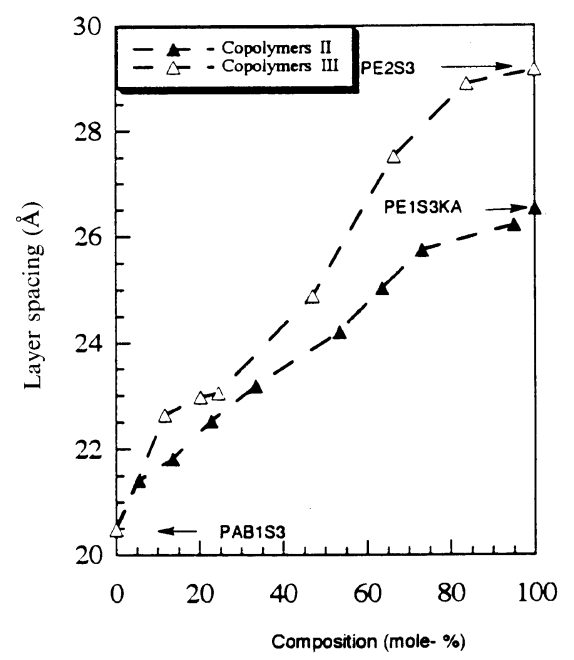

Figure 13. Relationships between the layer spacing $\left(d_{1}\right)$ and molar compositions of copolymers II and III.

tic of smectic phases. ${ }^{9}$ Hence, the polarized optical micrographs and thermal data are apparently insufficient for complete description of the structures of copolymers III. Figure 13 shows the relation of layer spacing with compositions of the copolymers II and III. The variation of thickness of the smectic layers with $R_{1}$ content presents positive deviation from linearity. Nonetheless, as seen in the copolymerization of smectogenic and nematogenic monomers with identical cyanobiphenyl mesogenic groups by Kostromin and Kozlova, ${ }^{4}$ due to the overlapping of the mesogenic groups, the thickness of the smectic layer increases linearly with smectogenic group content.

\section{CONCLUSIONS}

Thermal data and polarized optical observations cannot serve as basis for the final determination of 
mesophase type. Using copolymerization of two monomers of different smectogens, one can adjust mesophase properties and liquid crystalline molecular packing order.

Acknowledgments. We thank Dr. Sun Ma, and Miss $\mathrm{Ru}$-Zong Wu for their help in carrying out the ${ }^{1} \mathrm{H}$ NMR spectrum measurements and Dr. Bing-Hwai Hwang and Miss Show-Yueh Lee for help in the X-ray diffraction measurement. We are also grateful to the National Science Council of the Republic of China for financial support of this work (NSC-83-0117-C-230-001E). We also thank to Tim Person and Professor Morton $\mathrm{M}$. Denn for reading the manuscript and making many helpful suggestions.

\section{REFERENCES}

1. V. P. Shibaev and N. A. Plate', Adv. Polym. Sci., 60/61, 215(1984).

2. G. Hardy, K. Nyitrai, and F. Cser, Abstracts of Papers, The 5th Liquid Crystal Conference of Socialist Countries (in Russian),
Vol. 2, Part 1, Odessa, 1983, p 98.

3. H. Ringsdorf and A. Schneller, Br. Polym. J., 13, 43 (1981).

4. S. G. Kostromin and E. Yu. Kozlova, Abstracts of Papers, The 1st All-union Symposium on Liquid-Crystalline Polymers, Suzdal, 1982, p 48.

5. H. Ringsdorf and R. Zentel, Abstracts of Communications, The 27th International Symposium on Macromolecules, Vol. 2, Strasbourg, France, 1981, p 969.

6. G.-P. Chang-Chien, J.-F. Kuo, and C.-Y. Chen, J. Polym. Sci., A, Polym. Chem., 31, 2423 (1993).

7. G.-P. Chang-Chien, J.-F. Kuo, and C.-Y. Chen, Proceedings of the 14th R.O.C. Polymer Symposium 1991, C.I.Ch.E. Semiannual Meeting, Vol. 2, 1991, p 621

8. P. A. Gemmell, G. W. Gray, and D. Lacey, Mol. Cryst. Liq. Cryst., 122, 205 (1985)

9. P. A. Gemmell, G. W. Gray, D. Lacey, A. K. Alimoglu, and A. Ledwith, Polymer, 26, 615 (1985)

10. V. P. Shibaev, Ya. S. Freidzon, R. V. Tal'roze, and N. A. Plate', Preprints, International Symposium on Macromolecules, Florence, Italy, Litografia Felici., Vol. 3, 1980, p 310.

11. G.-P. Cheng-Jeng, J.-F. Kuo, and C.-Y. Chen, J. Appl. Polym. Sci., 47, 781 (1993).

12. G.-P. Cheng-Jeng, $\mathrm{Ph}$. D. thesis, National Cheng-Kung University, 1992. 